\title{
A Telephone Operator at a Sunshine Workshop
}

\author{
Huiran Li
}

\section{Interview with Ms. Y's Mother}

Ms. Y, female, born in 1986. Only child, mild intellectual disability. Graduated from a special education school in Shanghai in 2002 and started working at a Sunshine Workshop of a subdistrict in Shanghai in 2014.

Interviewee: Ms. Y's mother

Interviewer and writer: Huiran $\mathrm{Li}$

Interview dates: October 29, 2016 and January 12, 2017

Interview place: McDonald's, Bauhinia Square, Yangpu District, Shanghai.

\section{A Newborn Saved by Doctors}

Q: How did you get to know your husband?

Y's mother: We got to know each other through a matchmaker. He returned from a farm in Heilongjiang Province and worked in the production unit. It was hard work and poorly paid. I' $m$ a local here and younger than he is. I worked in a textile factory at that time. We got married after about 1 year, but we were not well off. Half a year later, I was pregnant. I was very happy when I found this out (with a happy smile).

Q: Did you have prenatal check-ups in those days?

Y's mother: I did have a monthly prenatal check-up, but it didn't reveal any problems, only that the baby was a bit small.

Q: The baby was smaller than normal, no other problems...

Y's mother: No, no. When I was going into labor, the doctors said my cervix was not open, but they didn't induce labor. She was delivered through C-section on May 3. When she was taken out, she cried a lot and her voice was loud. In the next day, within $24 \mathrm{~h}$ after her birth, the doctors found that her face and body were purple, and her cry was strange. They gave her emergency treatment. She was not so well after that.

H. Li $(\bowtie)$

East China Normal University, 3663 Zhongshan Bei Ro., Shanghai 200062, China 
Q: After she was saved, did you and your husband take good care of her?

Y's mother: Yes, we took good care of her. It was paramount. After her birth, I quit my job and looked after her every day. When she grew up a bit, I did odd jobs here and there, in addition to taking care of her.

\section{Exhausting Resources for Nutrition}

Q: Is your daughter always in poor health?

Y's mother: Unfortunately, yes. She was in poor health when she was little. Before she was about 2 years old, she often had colds or diarrhea, so we frequented hospitals. My mood depended on her health. I felt so worried about her throughout those years.

Our economic condition was not good at that time, but we spent a lot to buy nutritious food to gradually improve her health. We fed her various vegetables, bean products, date juice, milk, eggs, fish, shrimps, beef, and other foods that are good for brain development.

When she grew older, she wasn't allowed to have snacks, only after dinner. We adults kept all the nutritious food just for her, since she had a low birth weight of only $2.6 \mathrm{~kg}$ and we hoped she would grow healthier. Gradually, her condition was better when she grew to be 4 or 5 years old and basically okay at the age of 6 . She didn't have any serious diseases. It's just that her constitution is a little bit weak.

Q: When did she learn to walk and talk?

Y's mother: She toddled when she was 15 months old. Shortly afterward, she was able to say papa and mama. The first time when she called me mama, I was extremely happy and excited (with a happy smile on her face). I can still recall that feeling now! She wasn't an obedient kid, but there were funny stories. Our conversation might be like this: "Why don't you behave yourself?" "Because you often spank me." "But I spank you because you don't listen to me." "I won't listen to you anyway. Also, why did you give birth to me? I can just go back to your tummy." She was very stubborn. She hated criticism, favored praise, and could bear grudges. In her first grade, she was bullied by her classmates, but didn't dare to fight back. In the end, she simply refused to talk to them. That showed how stubborn she was.

Q: Could she take care of herself as a kid?

Y's mother: She was able to brush her teeth, wash her face and feet when she was about seven, and wash her hair when she was about ten. Before that, I helped her with these things.

\section{Preference for Transformers Over Dolls}

Q: Did she have any problems in kindergarten?

Y's mother: She went to an ordinary kindergarten. Sometimes she played with other kids, but for most of the time, she preferred playing alone in a corner. Teachers said that she was an introvert and seldom talked. She didn't like to communicate with others, either. That was typical slight autism. For 3 years in kindergarten, this didn't change. If her teachers assigned any homework, she didn't always tell me.

Both her teachers and I told her to be active and open, but it didn't work. She simply said she didn't like talking. Still, she made some good friends. A kid who lived upstairs was her playmate. The two of them played building blocks and sang 
together. As for the older kids, she simply ignored them. That was how she spent her days in kindergarten until the age of five.

At that time, her favorite toy was Transformers, in addition to other toys for boys, like origami, guns, yo-yo, and cards. She liked playing with boys. I asked her why. She said boys were straightforward, while girls were too coy. I joked, "How I wish you were a boy! (laughing heartily)" I also bought her 100- or 200-piece jigsaw puzzles. Sometimes she could fit them together. In a word, I bought her everything she wanted, as long as we could afford it. CDs, a CD player, and a radio were also bought for her. She didn't like those things which were generally for girls, dolls included. Now she knows better.

Q: What was your typical day like when she was little?

Y's mother: In the morning, I prepared her breakfast. Then I selected her clothes and taught her to dress, which she learned gradually. After she brushed her teeth and finished her breakfast, I took her to kindergarten. In the afternoon, I picked her up and sometimes we walked around. After getting home, I cooked and we had dinner. Then we watched TV, took another walk outside, went home, washed our face, brushed our teeth, and finally went to bed. That's typical for my day.

Q: So, you have been taking care of her alone. Do you have any helpers?

Y's mother: Only me. Her dad had to work. My parents had to take care of several other kids and her grandmother was too old to take care of her. Kids like her tend to be hated. Only parents are patient enough. I took care of her until she graduated at about 18 , because I didn't believe in others.

\section{Transferred to a Special Education School Due to Poor Academic Performance}

Q: When did you notice her differences from other kids?

Y's mother: When she was in the first grade. She couldn't focus in class, either fidgeting or sleeping. We thought it was natural to be fond of playing at her age. She kind of understood what the teachers taught, as she could remember all the pinyin. But she didn't like writing. I was told by her teachers that she refused to write, so I tried to force her. She could read correctly the 26 letters. Her handwriting was not bad, either.

Once, a teacher told her classmates, "Y's homework was not written by her, but by her parents. She doesn't like studying. I suggest that you don't play with her." When a teacher keeps saying that, a kid would feel inferior. Since you said I was like that, I would act like that. The situation remained like that until the mid-term exam, when she got a bit over 20 for the Chinese exam and over 50 for the maths exam. The score for other subjects was not so bad, though. Anyway, her teacher insisted that she should be transferred to a special education school.

$\mathrm{Q}$ : When her teacher prevented other kids from playing with her, did you talk with the teacher?

Y's mother: I didn't know about it until two other parents of her classmates told me, but $Y$ had already been transferred to a special education school by then. Her teacher never told me, but simply stressed that my daughter should take extra lessons after school. However, I couldn't afford it back then. So, I didn't employ any tutors, but taught her together with my husband. Sometimes I taught her writing and asked 
her to write again until I was satisfied. She knew pinyin well and she could spell the characters according to their pinyin. I also taught her numbering and arithmetic, counting from 1 to 100 . Every evening after dinner, I would teach her for about $1-2 \mathrm{~h}$.

Q: Was she eager to learn?

Y's mother: No. She started playing and playing once I wasn't watching her; and she wouldn't start her homework until I was back. She was always eager to play outside, but hated studying. She got spanked for this many times.

Q: How long did she stay in the ordinary school?

Y's mother: Just 1 year. Actually, she could catch up with her classmates, and we expressed our wish for her to stay, but her teacher insisted that she could only study at a special education school since she fell behind. We knew the truth was that the teacher felt shamed and was prejudiced against my daughter, considering her as a drag on the class. It was the teacher who forced her to leave. Considering the high school workloads at that time, I also tried to suggest that my daughter be transferred to another ordinary school. It was refused, however, by the teacher, arguing that my daughter was a poor learner, who would only be accepted by a special school. He even said he had arranged it for us.

This teacher was mean. Apart from my girl, he also transferred another boy to the special education school. He could do so if the student was considered a bad performer and made no progress after receiving extra lessons from him, but what he did instead was to make the kid leave directly at the critical moment when the kid was about to become a second grader.

Q: Have you ever considered taking her to a doctor and trying to transfer her back to an ordinary school?

Y's mother: Yes. We took her to Longhua Hospital. The doctor tested her IQ twice and her scores were a bit over 50 . This score, according to the doctor, was lower than normal, indicating the level of a kid of 5 or 6 years old. Learning this, we were worried (in a sincere tone). We took her to the same hospital again for a head CT scan. The doctor said that her fontanel was not completely closed, and she had mild ADHD and suffered from attention deficit. So, to help with her brain development, we gave her traditional Chinese medicine and nutrient supplements, which indeed had some positive effects. To deal with ADHD, I still gave her traditional Chinese medicine for about 4 or 5 years till she finished elementary school. As she grew older, it was more possible to make her behave sensibly.

People would always hate you when you had a child like this, right? Some meddlers would say how come you had a silly child. Gossip always existed. Even some of my siblings would hide their discrimination in my presence, but criticized her as foolish behind my back. Though she didn't know about these, I felt quite uncomfortable. Knowing this reality, I would try not to talk to them, avoided them, but still warned them not to speak evil of my daughter. Anyway, I was sensitive to their contemptible comments. We do not see each other much now.

Whenever I see kids like my daughter being bullied, I go blame the bully, "What's the point of you hurting the kid? These kids are already wretched," and chase the bully away. In my eyes, these kids are like my own daughter. If my daughter is bullied, I feel upset as well. Sometimes, I even felt uncomfortable when my mother asked my 
daughter to do housework. I mean it. I just couldn't understand why they wouldn't treat my daughter the same as everybody else. They are common people. You may not care about her, but at least I do. As for her dad, he didn't tell his colleagues about our daughter due to his concern about reputation. Thus, all his colleagues just thought that my daughter didn't like studying.

Q: How was her health after she went to elementary school?

Y's mother: Very good. She grew to be over $170 \mathrm{~cm}$ (laughing heartily). None of the other three children in my extended family outgrew her.

\section{A Helpful Monitor for 5 Years}

Q: What was she like in the special education school?

Y's mother: She was originally studying in a school in Pudong District. Later, we moved to Yangpu District, so she was transferred accordingly. She went to the special education school when she was 8 and graduated at the age of 17 . Her performance at school was not bad, as the lessons, after all, were easier than in ordinary schools, and she might have matured. Anyway, this is your own child. There's nothing you can do about it. It was just an event of small probability like when you win the lottery, I guess. Nonetheless, I'm still fortunate. She simply doesn't like studying, but still performs better than other kids in other aspects.

Q: How were her studies?

Y's mother: Not bad. Her scores were 90-plus, 80-plus, better than many classmates of her age. In the beginning, I forced her to study hard, and she begged me not to do so, saying that she didn't want to study. I told her she must study, because she couldn't afford to be illiterate. Then she still begged me not to put any more pressure on her. So, in the end, I was like, forget it. From then on, I stopped pressing her and allowed her to study as she wished.

Q: Was she a leader in her class?

Y's mother: She was the teacher's assistant, responsible for collecting students' homework and correcting it. In the fifth grade, she became her class's monitor. She oversaw various duties, like distributing stuff, homework, and test papers, and also making the students line up for dinner and ladling food. This role gave her many opportunities to communicate with her teachers, but she didn't do it very often. She just tried her best to finish the tasks entrusted to her and reported to her teachers. Also, she didn't think much of teachers' praise and didn't like to be in the limelight (laughing). She was the class monitor all the way up to the ninth grade.

Q: How many students were there in her class?

Y's mother: More than 30. Some students had severe intellectual disabilities and some were mild. Some kids suffered from cerebral palsy and Down syndrome. My daughter felt sympathy for them and helped them with many things they could not handle, like pouring water, fetching things, and helping them walk.

Q: What courses did she take in the special education school?

Y's mother: Chinese, maths, cooking, pastry, music, physical education. There were no English lessons. Generally, her performance was good, with the scores of Chinese and maths ranking the first or second, but her painting was not. She liked to work with her hands. She could make excellent paper birds, just like a boy. 
I always accompanied her to school and back home. She could walk home alone, but I simply didn't feel at ease. She was audacious, and often went out whenever possible. She could stay outside for hours without feeling scared. But I was worried. I asked her, "Aren't you scared? What if you meet bad guys?" She said, "I will not talk to them. I'll just ignore them if they say something. I'll keep walking and never look back."

Q: Did her school organize any activities?

Y's mother: Yes. They went on outings every year. They went to the Forest Park, the Safari Park, the Xijiao Park, and the Oriental Pearl Tower. They also had sports games and gymnastics competitions. She didn't like ball games.

Q: Did she have any good friends?

Y's mother: Yes. A couple of friends. Boys and girls. They played fighting. She also liked to listen to music, or read novels.

Q: Do you know what novels she was reading?

Y's mother: I had no idea (laughing). Her things are kept neat and her books are kept from us. I never tamper with her stuff. I'm wise.

She hated homework so much that she would not even raise her head if I told her to do her homework. She just liked playing and reading. She might read novels for 1 or $2 \mathrm{~h}$ without moving a bit, and she would cry if I tore her novels when she played too hard. Once, she refused to follow my instruction and it was impossible to talk sense into her, so I told her, "If you cannot get rid of your bad habit, I will tear your books. I mean it." She didn't believe it, but changed her mind once she saw I wasn't bluffing. I said, "As long as you finish your homework, I will not meddle in any of your affairs. Studying is the top priority." She finally understood. She would show me the finished homework when I got home, and if I was satisfied, I would allow her to play as she wished.

Q: Did she have pocket money to buy books?

Y's mother: Sometimes she asked me to buy books for her and sometimes she used her own money. She also had pocket money from her dad. Most books were bought by me. I bought her everything she wanted. Nowadays she reads novels on her mobile phone. I don't care what she is reading as she's already married. I don't want to interfere with her affairs. I just teach her how to respect her mother-in-law.

Q: What else did she do when she didn't have classes?

Y's mother: She helped me wash the dishes. Since she was about 15, I taught her how to cook. I gave her instructions and she cooked the dishes one by one. Now she can cook various vegetable dishes and soups.

Q: Have you ever taken her traveling?

Y's mother: Yes. We have been to Nanjing and some other places. We also took her to parks when we were not well off in her early childhood. We visited the Jinjiang Amusement Park, where she took various rides. Being brave, she preferred exciting rides that rotated 360 degrees a lot. Normal ones were not her thing. We also went to Changfeng Park, Xijiao Park, Heping Park, and Zhongshan Park, etc. She would try all the amusement facilities in the parks. Sometimes she went to parks with her friends, but less nowadays. Sometimes if she expresses her wish to go there again, I just said, "Let's go have fun. I'll take you there." 


\section{A Telephone Operator at the Sunshine Workshop}

Y's mother: After she graduated from the special education school, upon recommendation by the Disabled Persons' Federation (hereinafter referred to as the Federation) of Yangpu District, her dossier was affiliated to a company in Shanghai. I didn't know what the company was engaged in. She could receive a minimum monthly salary, increasing from about 1,000 yuan initially to more than 2,000 yuan later. It was like this for 7 to 8 years. And she didn't do any work during those years. She just stayed at home.

Later, upon recommendation by the Federation of Yangpu District, she worked for about 1 month at a bakery, where she was asked to do all the dirty and hard work. This made her so tired that she wanted a rest, so she took 2 days of leave. On the third day, she sprained her ankle on her way to work, but the bakery claimed that she had canceled her contract with them since she was absent from work without permission. This way, the Federation removed her affiliation ${ }^{1}$ and only provided her with a minimum subsistence allowance. She rested for about a year to recover and went to the Jiangwan Sunshine Workshop afterward. Her job was to classify threads based on their colors as per the samples, wind the threads onto a board and pack them for sale. She worked there for more than a year.

Q: Why did she transfer to this current Sunshine Workshop?

Y's mother: Because it's the center of our own subdistrict. But she herself actually preferred the Jiangwan Center, where she enjoyed herself a lot with more good friends. There was an old man working at the District Federation who "forcibly" invited her back to the newly established Sunshine Workshop of her own subdistrict. This way, when she needed to participate in any performances, she could ask our subdistrict for leave, without the need to go to other places.

My daughter came to this Sunshine Workshop in 2014. A thorough cleaning was the first task soon as everyone arrived in this new center. After that, for about 5 to 6 months, she folded towels and put them into boxes. Then she folded paper boxes and then strung beads. Stringing beads and folding towels were contracted from other organizations. After stringing beads for several months, my daughter was assigned a new task. She needed to call the households which did not pay their telephone bills in time and remind them to settle their bills. This is what she does every day since then (see Fig. 1).

There are more than 20 people at the Sunshine Workshop. Seven or eight people do the same job as my daughter. Y goes to work every morning at 8:30 and makes phone calls for over an hour. She has lunch there and starts making phone calls from 1:00 in the afternoon, until 2 o'clock. Then she rests and goes home at 3 o'clock. If there is no incoming call, she always fiddles with her mobile phone, watches movies or reads novels on her mobile phone. At home, she plays video games and watches TV series. She likes costume dramas like the Romance of the Three Kingdoms.

\footnotetext{
${ }^{1}$ Since one person cannot be employed by more than one organization simultaneously, the editor presumes that the Disabled Persons' Federation of Yangpu District removed Y's affiliation to the company when she was actually employed by the bakery. Then she became unemployed after leaving the bakery, thus claiming the subsistence grant distributed to the unemployed disabled people by the government, which is equal to the "minimum subsistence allowance" mentioned by her mother.
} 


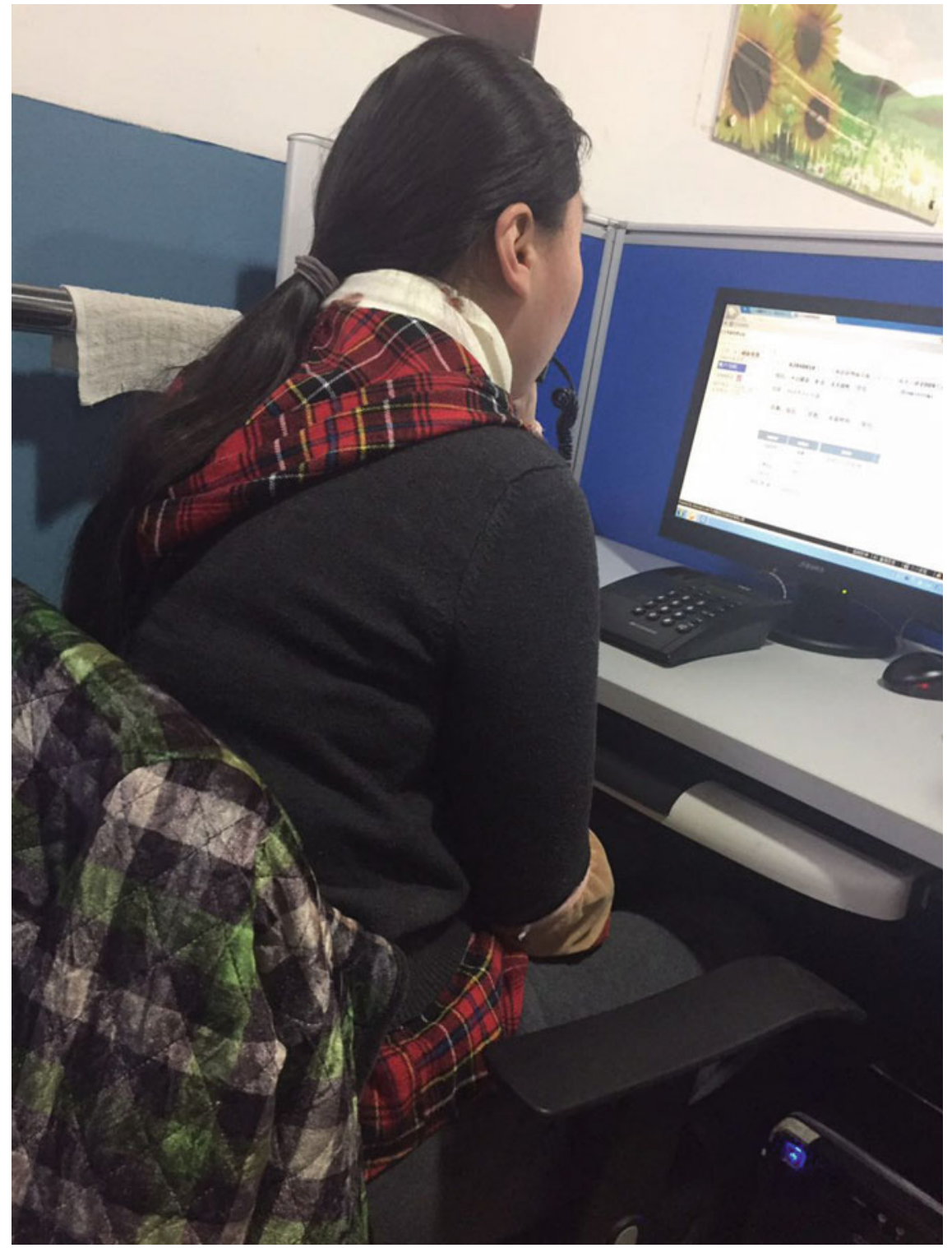

Fig. 1 Ms. Y at work

Q: Did she have any difficulties in adjusting to her new job as a telephone operator? Y's mother: Yes. She was reluctant. In the beginning, she didn't want to answer the calls as some callers were polite, while some others were ill-tempered people who kept cursing. She felt she was unlucky, saying that, "I was often cursed at, and 
it makes me so sad". After about half a month of hesitation, she still didn't want to take the job, saying it was frustrating and annoying.

I said, "There's no point in feeling frustrated. Just ignore them. People have different personalities and ill-tempered ones do exist. Don't take it personally. You have no choice. This is your job. Let them curse. Forget it as soon as you hear it. Any job can be frustrating at the beginning, but you just need to adjust to it until you ultimately feel at ease. If you don't take the job, will you just stay at home? It's not that bad. You don't like talking, right? But this job makes you talk. You can practice your speaking skills through this."

Her teacher also said this job was very good and that she would adjust to it over time. Her teacher said, "Y, you are smart, but you don't talk much." I told her teacher, "You have to press her. Be strict with her. You can spank her if she doesn't behave herself." Of course, she wouldn't spank her. Ha, Ha! Her teacher likes her. Her mother-in-law also tried to persuade her. Gradually, she got used to it. With 2 years of experience now, she talks much more and expresses herself much better, from simply a few sentences to a paragraph. She also talks politely.

Q: How does she get along with her colleagues?

Y's mother: Not bad. They help each other. If any of her colleagues is depressed, she will try to comfort them. Compared to other kids, she is well behaved. She is also very kind. Once, a young girl of the District Federation with diabetes got worse after having desserts banned by her mom. My daughter would visit her in the hospital with gifts. In another case, a kid needed hemodialysis due to a complication. Most people donated 2 or 3 yuan at the teacher's request, but she donated 50 yuan, all earned by her at work. She was already more than 20 by then. She also normally saves several hundred yuan given by the Federation each quarter for those in need.

Q: Does she receive a monthly salary?

Y's mother: My daughter earns a little more than 2,000 yuan each quarter. Her husband is affiliated with a company, earning a little more than 2,000 yuan each month.

Q: Now that she earns a salary, has she bought you any gifts?

Y's mother: Yes. After she got married, she bought a mobile phone for me as a birthday present and a short-sleeve shirt for her dad. She generally spends more money on me than on her dad. We asked her not to buy things for us when she didn't earn a lot before getting married, but now I'll happily accept her invitation to a dinner if we go out on the weekend. I'm happy to receive gifts from her. She has become more mature since getting married. I tell her not to act like a kid now that she's married, while she replies she will always be a kid in my eyes.

\section{Favorite Entertainment at the District Federation}

Y's mother: She went to the District Federation half a year after her graduation. The Federation had a waist drum team and she joined in the second batch over a decade ago. She is a quick learner and plays quite well.

Other activities also include singing and dancing. She can sing many old revolutionary songs like The East is Red, The Red Army Song, Red Star Shines, and Three Rules of Discipline and Eight Points for Attention. I can't remember the titles 
(laughing). They don't often sing pop songs. As for dancing, it's mainly about Chinese martial arts, Chin Woo gymnastics, Xinjiang dance, Korean dance, and A Grateful Heart dance. I can only remember these.

She also bakes cakes, pastries, and cookies, not Chinese pastries. She once learned how to cook mantou (Chinese steamed bun) at school. They had cooking competitions every 1 or 2 years to select the best chef. Teachers would take several eggs for all the participants, namely every student, to boil or fry, to see how well they can cook. Parents would then have a taste. My daughter acted like a good cook, but she was a bit rushed. The final result tasted not bad actually. She can cook scrambled eggs with tomatoes, stir-fried vegetables, and boiled eggs. She was neither the top, nor the bottom, but slightly better than the average. She has also learned some basic English for 3 to 4 years, like hello, snow, or numbers, etc. Her English is not very good, as she didn't know the alphabet and never learned it before like those studied in ordinary schools. She is learning from them bit by bit.

Q: Does the Federation arrange for her to participate in performances? Does any TV station come to record their performance?

Y's mother: Yes. There were also pop singers. The TV stations made programs showing their performance, like Chinese Kung $F u$ and dragon dance, my daughter included. They went to the Shanghai Television Station to perform and the show could be watched from both the Shanghai local channel and the CCTV. I missed it, but my daughter saw a segment. The final performance normally looked much better than rehearsal. The moment they started beating their drums, the scattered crowd became silent.

Q: Do they have teachers teaching them singing and dancing?

Y's mother: Yes. The teachers are also parents. They take great pains to help the kids learn the waist drum and have the kids practice over and over again. The teachers are all nice and patient people. My daughter likes them very much and respects them. One of the teachers, Ms. Zhou, treated the children there as her own kids, teaching them again and again. This arduous effort won her great respect from among the children. My daughter may keep some secret from me, but not at all from her teachers. She considers them like me with much affection. The kids are under strict regulation, while my daughter believes it is for their own good, so she always follows the teachers' instructions. Every year, she also goes on outings with the teachers. This year, they went on a 3-day trip to Zhangjiagang. She enjoyed it a lot. The scenery there was beautiful, she said, but I haven't seen the pictures.

Q: Does she receive a subsidy for participating in activities of the Federation?

Y's mother: Not necessarily. Some kids who live in poor conditions and travel a long distance may receive a meagre travel allowance of about 2 or 3 yuan each time. One year, every kid received allowances, but that was only once. When they participated in contests or performances, the organizers would pay them a little money, about 20 yuan. In most cases, there is no allowance.

Q: Does your husband go with your daughter when she goes to the Federation on weekends?

Y's mother: No, she goes there alone. Her dad is physically disabled, so he can't carry out activities like that. Now she leaves from her mother-in-law to the Federation, 
while I go there from my house. Rain or shine, you can count on her to be there, even when she is ill (laughing). She refuses to ask for leave as she feels happy at the Federation with the teachers. She always sends her holiday wishes through text messages to them one by one during festivals, including on New Year's Day.

\section{Participation in Special Olympics Recommended by a Teacher}

Q: Did your daughter participate in the 2007 Special Olympics?

Y's mother: Yes, she did. She took part in racing and badminton, ranking first and third, respectively.

Q: How did she train?

Y's mother: She had work to do it at the Sunshine Workshop, so she had to take leave to train. It was a hard time for her. Actually, she didn't take interest in sports, but her teacher insisted that she should take part in the competition. I told her, "You're asked to go, because the teacher hold high opinions of you. You must do your best and win honors for your teacher." So, she took the training seriously. At the training center, coaches from sports clubs trained them to run and serve badminton for over a month. During that period, she trained from 1:30 to 4:30 in the afternoon every day after lunch. She felt tired, because she didn't do much exercise before.

Q: Did many people from the Sunshine Workshop participate in Special Olympics?

Y's mother: Not many. Around a dozen. They gathered at the District Federation and went to the training center together.

Q: Did she compete with Chinese or foreign athletes?

Y's mother: Chinese athletes. I was at work during her competition, so I didn't go to the venue, but watched the live broadcast instead. I started working after she went to work at the Sunshine Workshop, which left me more time to myself. I did sanitation work for around 10 years before I retired.

Q: How long did the competition last?

Y's mother: About a week. She participated in two events, each had four or five rounds, including the preliminaries and finals. I still keep the gold and bronze medals. it?

Q: The 2007 Special Olympics was a sensation. Did journalists interview her after

Y's mother: No. They interviewed the District Federation. She wasn't interviewed. She is a bit slow after all.

\section{A Helper to Her Mother-in-Law in Business}

Q: Ms. Y is married, right?

Y's mother: Yes, ha ha (smiling, feeling shy). They were married in 2012. Her husband is only physically disabled with walking problems. He also works at the Sunshine Workshop, but not as capable as my girl. After getting married, my daughter lives with her in-laws. She gets along well with them. She can go to the Sunshine Workshop from her home in $5 \mathrm{~min}$, while my home is only four stops away from her mother-in-law's. Normally, she helps her mother-in-law with the small business after getting off work at 3 p.m.

$\mathrm{Q}$ : What kind of business is her mother-in-law engaged in? 
Y's mother: She sells snacks like fried chicken and milk tea, and liquor. Her mother-in-law was a natural businesswoman, who adapted one of her rooms as a store. Y helps her every day. They are very busy, but they close the store before 6 o'clock. Then her mother-in-law cooks dinner and washes the dishes. After cleaning, she goes walking for a while till 7 or 8 and goes to bed after taking a shower.

Q: How did your daughter and her husband meet and fall in love?

Y's mother: There is an episode. Once, she sprained her ankle on her way to work, and her foot was fractured. At that time, they were dating. Since I was busy fitting up my house, he immediately called his mother, who sent my daughter to the hospital for an X-ray right away. The doctor found that my daughter had a dislocation, which required surgery. His mother was really considerate and tried her best to ask for help from her contacts, so that my daughter had the surgery the very next day. His mother took good care of my daughter for a month, for which my daughter was extremely grateful. Then the two youngsters got married about 1.5 years after they started dating.

Q: How do you feel, now that your daughter is married?

Y's mother: I am happy, of course. But I'm also anxious. I need to take care of her regardless. She's inexperienced; I constantly worry about her. I need to tell her how to deal with daily life. When such a child becomes independent, you can never relax. I'm always afraid that her husband's family might take advantage of her. I feel concerned even now.

Q: Have they considered having a baby?

Y's mother: My daughter doesn't want one. She said, "Both of us are disabled. What if our child is also like this? I am unable to take care of a child like me. It is unfair to the child." What can I say? She doesn't want a child.

Q: Does your son-in-law have any other problems apart from physical disability?

Y's mother: He only has a problem with his legs. His legs were disabled when he was very young due to high fever. Two operations couldn't even save the legs. He's lazy, incredibly lazy. He needs help with everything. If you don't pour water for him, he would never go for it. He is just like that. Neither does he want to do any exercise, nor can he bear any hardships (sighing). I told my daughter, "How can you bear to be treated like that? His legs are disabled, not his hands. His mother doesn't want him to suffer, but you should have scolded him since you were a couple. Who is he going to rely on when his mom is old? Does he want his old mama to take care of him?" He is not only lazy at home. He also asks my daughter to pour water for him when they are at work. She has no choice.

\section{Mother and Daughter Doing Exercise to Lose Weight}

Q: When does she come to visit you after getting married?

Y's mother: She is busy working during the day. When she gets off work from the Sunshine Workshop, after having dinner and washing the dishes, she'll call me while walking for exercise at around 7 . We usually talk for about a minute, just a few sentences. I tell her to keep her home clean and tidy. All the housework is done by her at her home, but she is not perseverant and lacks initiative. I need to remind her. She doesn't wash her duvets until I tell her to do so. We often meet on weekends. 
Q: Does she stay at the District Federation for the whole weekend?

Y's mother: Yes, both mornings from 8:30 to 11:00, but not in the afternoon.

Q: What does she do in the afternoon then?

Y's mother: We often take her out to have fun. We just wander here and there, seeing different parts of the city. We want to relieve her boredom by taking a walk. In recent years, she also sends me holiday wishes. She's able to understand my hardship in raising her up.

The cause of the fracture I mentioned before was because she fell, because of an oil stain on the ground. After the incident, she was in bed for over a month before the steel bars were taken out. Obviously, she didn't do much exercise during the period, but just sleep after eating. That was how she gained weight. She didn't have regular meals. She skipped breakfast and supper from time to time, but she didn't care. I told her, "You can't skip meals like that. How can you keep healthy without regular meals? It matters the most. You must have a bowl of rice every day, plus some vegetables and meat. Otherwise, I'm afraid that you'll suffer like your classmate at the District Federation. You can keep skipping meals if you want to repeat the failure of that classmate." I just scared her like that.

After she gained some weight, her blood sugar increased accordingly, which may lead to diabetes. So I took her to see doctors. After treatment for about 2 months, the doctor said that her blood sugar was not too high, only a bit high after dinner, which was normal. Doctors told her to do exercise, otherwise, ...

So, I started to do exercise with her every day. We walked for more than an hour each time. She was reluctant to walk for exercise in the beginning, then I asked her to walk with me. After walking together for about 2 months, I told her, "From now on, you need to walk by yourself and rely on your own effort. You must persist if you want to lose weight. Perseverance leads to victory." She followed my advice. Once, she was gaining some weight. I told her, "You need to exercise harder. You are fat again." She replied that she'll try harder. I call her like this everyday to remind her to walk for exercise.

Now she walks all by herself. In the morning, she goes walking for about $40 \mathrm{~min}$ after breakfast. In the evening, about half an hour after cleaning the dishes. I tell her the evening exercise matters the most, as fat won't accumulate if she keeps walking. I also say that, "You can count on no one else, but yourself to lose weight. You can walk without other's companionship. Have confidence in yourself." Now she is much thinner. She said she wanted to keep walking until she weighed $62.5 \mathrm{~kg}$. I said, "Go ahead." You must have confidence in yourself no matter what you are engaged in. Otherwise, you'll achieve nothing.

She kept walking, without controlling her diet. She ate both vegetables and fruit. In about 6 months, her weight was reduced to $65 \mathrm{~kg}$ from $75-80 \mathrm{~kg}$. God, she was really fat previously. Now she weighs about $65 \mathrm{~kg}$ and her blood sugar level is back to normal. She is happy about this. She still walks alone for exercise every day, both in the morning and evening. I also do the same. I told her, "I'm urging you for your own good. You should be thankful." And she said she really was. She sent me holiday wishes by text message and said I was pushing her for her own good. She is now slimmer than before. 


\section{Interview with Ms. Y's Teacher}

Interviewee: A teacher from the Sunshine Workshop of a subdistrict in Shanghai Interviewer and writer: Huiran $\mathrm{Li}$

Interview date: December 7, 2016

Interview place: A Sunshine Workshop of a subdistrict in Shanghai

Q: Would you please briefly introduce to me the students of the Sunshine Workshop?

Teacher: There are two groups. One group refers to those who can make phone calls, while the other group stays in the classroom.

Students who can make phone calls can handle simple jobs, but they are only auxiliaries. It is often known as informal employment. They enjoy the minimum standard of five social insurances from the government, amounting to 1,300 to 1,400 yuan each month. They also have an allowance of over 800 yuan. Altogether, that is 2,190 yuan. But ultimately, they can receive only over 800 yuan. The minimum living standard is adjusted annually, so is the amount of living allowance. It is much better than before, when there was no such allowance at all. The government has invested a lot in this field.

As for the second group of students, they do not undertake simple jobs, so they don't enjoy social insurances. They only have the living allowance.

Q: Can you tell us some basic information about Y?

Teacher: Y has mild intellectual disability. She previously worked at the Jiangwan Workshop, and came to this workshop since its establishment, making her a senior staff member here. She just lives across the street. She can handle simple jobs like making phone calls. She receives the five social insurances and the living allowance of over 800 yuan. She also participates in the activities at the District Federation every Saturday and Sunday morning and has been with the waist drum team for a long period. Overall, she's good with a high attendance rate. She always comes unless she's ill or has other difficulties.

$\mathrm{Q}$ : $\mathrm{Y}$ is married, right?

Teacher: Yes, her husband also works here. He is probably ill these days. Otherwise, you should be able to see him. His condition seems worse than hers. Or to be precise, his condition is the worst among the physically disabled students here. When we had activities, he often fell. We are very concerned, because we bear a lot of responsibility when we take them on an outing. We have two couples in the workshop. This is quite a small number. Strictly speaking, a couple is not allowed to work at the same workshop due to inconvenience in management. Both of Y and her husband were single when they joined the workshop. Later, they dated and got married before I came here. I learned about their story from other teachers of the Federation of the subdistrict.

Q: Is Ms. Y an introvert?

Teacher: Yes. She is intimate with me. As a teacher of special education students, we need to understand their characteristics. When I first came here, she didn't get along well with her previous teacher. There had been tension and even quarrels 
between them. Afterward I had deep conversations with her and found that she was not bad. These students are a special group of people. You must use a different way to communicate with them. Ms. Y is willing to share all her secrets with me. We also talk a lot. I like the girl.

We have two types of students here. Students handling phone calls rarely communicate with those in the classroom, because the former have contempt for the latter, who are considered to be foolish and unable to start a dialogue. In fact, students handling phone calls just don't like to hang around with those in the classroom. So, the students in the classroom mostly play with each other.

Students handling phone calls are mostly kind guys, actually. Several of them are especially close. Unlike the past, when she seldom talked to others, Ms. Y is more open now. I told her, "You have to change. We are a group. This place is different from your home. If you keep everything to yourself at this place, it does you no good except for a different environment. You must learn to be included into our big family. All the students here are more or less the same. Otherwise, you won't be here. It doesn't make sense to despise others. You may not talk to them if you don't want to, but you still need to communicate."

She is a handy person. She can do her job very well when she is on duty or required to do some cleaning. The dishes are neat and tidy, and everything is in order. I think she can live an independent life. She washes her own clothes as well. At least she's already a married woman.

Sometimes, I talked to her while walking after dinner. She seemed to bear slight grudges against her husband as both of them are young people and only children, but her husband cannot do any job. I told her, "Now that you chose to marry him, that's your life. You need to take care of him, but he cannot do anything in return. You have to make a sacrifice." Actually, her husband is from a well-off family, it's just that he himself is seriously disabled. Sometimes, she said she regretted it. I said, "It is improper to say that. It's understandable if he became disabled after your marriage, but the reality is that he was like this when you first knew him. Now that you married him, it meant you had accepted him as he was. You must face your future life together. It's lucky that all your parents are still able to support you, otherwise you'd need to count on yourself. You should be prepared." I can tell that sometimes she feels unhappy about her mother-in-law. When she complains to me, I'll try to help her. Now she is much better. I told her, "As you grow older, you should be mature in all aspects." At least, she's already a married adult over 30. But deep down, she is still like a simple and naive child. When she encounters setbacks in life, she doesn't know how to handle it.

Q: I think she is overall very happy now.

Teacher: Yes. She had some friends at the Jiangwan Workshop, but fewer friends here. The situation is much better now. Previously, she didn't even communicate with people. I told her, "That way, you will feel lonelier and more bored. Don't always compare this place with Jiangwan." Now, she has got used to this place. She's basically meticulous, careful, and introverted. This might have something to do with her personality, family background, and her marriage. It is different to live together with your own parents than your in-laws. 
Q: Is she always handling phone calls these years?

Teacher: She officially started handling phone calls in May 2014. From 2010 to 2014 , we undertook some simple tasks, like folding towels, processing disposable chopsticks and stringing beads. Now that we have undertaken this phone call project, we are unable to do those previous tasks, as there are not enough students in the classroom to finish everything in time. Originally, it was also the students now handling phone calls who did most of the work. Without them, the students in the classroom plus us teachers were still not enough as we had deadlines to meet. We didn't earn much through these kinds of tasks. It was about 0.01 or 0.02 yuan per pack of napkins. The quantity mattered more than the unit price.

The current task is much better. Other people envy us. The room is like an office, nothing short of that for people without disability. We all use new equipment installed by China Telecom. The computers are bought by us. Each of us has a passcode and our own seat. We work through a platform. Sometimes when the phone fails to get through, we have to move to another place. So, we have mobile positions.

Since they are disabled, they may find it inconvenient to press the buttons on the phone. So, we ask them to click the phone numbers on the computer screen instead. We also designed a headphone initially, but they didn't like it. They prefer a landline phone and consider it easier to use. If everything goes smoothly, they can finish a call within $30 \mathrm{~s}$.

They attended a training course by teachers from China Telecom and were required to pass an exam before taking the job. This way, they may feel certain pressure and be more careful on the job. Otherwise, they would not take it seriously. I also attended a training course. Later, when the original teacher left, I took over the responsibilities. I know about the business.

Now, they don't have much difference from ordinary people while making phone calls. Most of them didn't go to high school after graduating from junior high. So, due to limited education, they don't know a lot of characters, especially in the beginning. When talking over the phone, they might not be able to answer some of the client's questions. Now they have dealt with various cases, and they will report to me every week if they have any problems. Sometimes, I instruct them in relevant skills during weekdays. Now they can deal with all the clients' questions. It is very easy for them now.

Q: I don't think she has any problems answering the phone calls just now.

Teacher: In fact, she has encountered questions, but she can answer them all now. In the past, when they first took the job, they didn't know what to reply and just froze there. It took some time. After all, it has been 2.5 years. They are much better and familiar with the job now.

Q: Where is their lunch from?

Teacher: From outside. It's ordered by our superior. ${ }^{2}$ They all have lunch here, rest, start working again at 1:30 and get off at 3 p.m. We have been working together for some time, and they spend more time with us than with their parents. So, in a

\footnotetext{
${ }^{2}$ The top-down hierarchical structure is District Federation, subdistrict Federation and subdistrict Sunshine Center.
} 
sense, we know everyone very well, no less than their parents. Overall, I think these students are not bad. They are willing to open their hearts to me and accept my advice. After all, they are all grown-ups. They are not children anymore.

Sometimes, we go out to have fun, like watching films. We go to a nearby movie theatre within walking distance once or twice a month. Last November, we took them to visit the film center in Songjiang. We also have many outdoor activities. The subdistrict Federation determines the schedule, while we will then take them to the destination.

Q: Okay. That's all for today. Thank you.

\section{Interview with Ms. Y}

Interviewee: Ms. Y

Interviewer and writer: Huiran $\mathrm{Li}$

Interview date: December 7, 2016

Interview place: A Sunshine Workshop of a subdistrict in Shanghai

Q: How long did you stay at the previous Sunshine Workshop?

Y: A year and a half. I didn't want to come back, but they insisted. I had no choice.

Q: Do you like your present job?

Y: I prefer my previous job of folding napkins at the Jiangwan Workshop. My present job is not bad, but I don't like talking. My previous job involved hands only, so we could chat while working, as long as it didn't affect our work. It was fun. People there were nicer. It was more fun at Jiangwan.

Q: You have been here for about 4 to 5 years. Are you always making phone calls?

Y: No. In the beginning, I packed napkins. You know, if a restaurant does not offer towels, they offer packed napkins. I also folded towels.

Q: You like puppies and kittens a lot, right?

Y: Yes. I like Pomeranian, Chihuahuas, and Yorkshire terriers. And the dogs with very short legs and no tail. They are fun. I like various dogs. I also like cats. I like puppies and kittens (playing with a kitten while talking).

Q: Besides cats and dogs, what else do you like?

Y: Nothing special. I like Scarlet Heart and Scarlet Heart 2. I also like old dramas and films, like Righteous Guards. Now you cannot find them on the Internet. I like various swordsman dramas. They are very interesting.

Q: Out of Scarlet Heart and Scarlet Heart 2, which one do you prefer?

Y: I like Scarlet Heart more than its sequel. I also like the heroine Shishi Liu. I don't know why, but I am somehow attracted to her. I just like her.

Q: Which hero do you like?

Y: One is Qilong Wu. I also like the actors of the eighth and the thirteenth princes. They are also good.

(A nearby student said the weather was good and it was like spring.)

Y: I think it is not spring yet. What about winter?

Q: Do you like the teachers in this workshop?

Y: Yes, they are not bad, but I prefer the teachers of the District Federation. 


\section{Observation of Ms. Y at the Sunshine Workshop}

Observation date: 9:00-15:00, December 7, 2016

Observation place: A Sunshine Workshop of a subdistrict in Shanghai

Observer and writer: Huiran Li

\begin{tabular}{|c|c|c|c|}
\hline \multicolumn{2}{|l|}{ Time } & \multirow{2}{*}{$\begin{array}{l}\text { Activity } \\
\text { Seated Tai Chi }\end{array}$} & \multirow[b]{2}{*}{$\begin{array}{l}\text { Remarks } \\
\text { Ms. Y practiced Tai Chi following } \\
\text { the instructions of a tutor. She was } \\
\text { very skillful. When the tutor asked } \\
\text { questions about the names of each } \\
\text { posture, Ms. Y listened quietly } \\
\text { while others answered. She didn't } \\
\text { say anything. Sometimes, she } \\
\text { mouthed the posture name silently }\end{array}$} \\
\hline 9:00-10:00 & 9:00 & & \\
\hline & $9: 20$ & $\begin{array}{l}\text { The tutor taught some new postures } \\
\text { and asked the people to practice }\end{array}$ & Ms. Y was learning carefully \\
\hline & $9: 50$ & She practiced Tai Chi to music & $\begin{array}{l}\text { Ms. Y's postures were standard, } \\
\text { and she could practice the whole } \\
\text { set of postures in a skillful manner }\end{array}$ \\
\hline \multicolumn{2}{|l|}{ 10:05-10:50 } & $\begin{array}{l}\text { She went to work and made phone } \\
\text { calls }\end{array}$ & $\begin{array}{l}\text { Ms. Y worked at the Disabled } \\
\text { Persons' Sunshine Call Center of } \\
\text { Hongkou District, Shanghai, under } \\
\text { the Department of Debt Collection } \\
\text { of China Telecom. Her job was to } \\
\text { inquire with subscribers, whether } \\
\text { they have received the telephone } \\
\text { bill for last month. Ms. Y worked } \\
\text { with concentrated attention }\end{array}$ \\
\hline \multicolumn{2}{|l|}{ 10:50-11:00 } & $\begin{array}{l}\text { Ms. Y took a rest and waited for } \\
\text { lunch }\end{array}$ & $\begin{array}{l}\text { Ms. Y fiddled with her mobile } \\
\text { phone, checked WeChat public } \\
\text { accounts featuring kittens and } \\
\text { puppies and talked to her } \\
\text { colleagues }\end{array}$ \\
\hline \multicolumn{2}{|l|}{$11: 00-11: 10$} & Lunch & $\begin{array}{l}\text { Ms. Y enjoyed her lunch silently. } \\
\text { She shared some of her food with } \\
\text { her colleagues }\end{array}$ \\
\hline \multicolumn{2}{|l|}{$11: 10-13: 30$} & Lunch break & $\begin{array}{l}\text { After lunch, Ms. Y cleaned her } \\
\text { desk and phone. Then, she went to } \\
\text { a path outside the Sunshine } \\
\text { Workshop, basked in the sunshine, } \\
\text { took a walk, patted the kittens and } \\
\text { chatted with her colleagues and } \\
\text { teachers. She took out her iPad to } \\
\text { read novels and check her WeChat. } \\
\text { She ate several walnuts }\end{array}$ \\
\hline
\end{tabular}


(continued)

\begin{tabular}{l|l|l}
\hline Time & Activity & Remarks \\
\hline 13:30-14:45 & $\begin{array}{l}\text { She went back to work and made } \\
\text { phone calls }\end{array}$ & $\begin{array}{l}\text { She inquired with subscribers } \\
\text { whether they had received the } \\
\text { telephone bill for last month }\end{array}$ \\
\hline 14:45-15:00 & Rest. Get ready to go home & $\begin{array}{l}\text { Ms. Y packed her stuff and said } \\
\text { goodbye to her colleagues and } \\
\text { teachers before she left the } \\
\text { Sunshine Workshop to go home }\end{array}$ \\
\hline
\end{tabular}

Translated by Min Cui

Open Access This chapter is licensed under the terms of the Creative Commons AttributionNonCommercial-NoDerivatives 4.0 International License (http://creativecommons.org/licenses/bync-nd/4.0/), which permits any noncommercial use, sharing, distribution and reproduction in any medium or format, as long as you give appropriate credit to the original author(s) and the source, provide a link to the Creative Commons license and indicate if you modified the licensed material. You do not have permission under this license to share adapted material derived from this chapter or parts of it.

The images or other third party material in this chapter are included in the chapter's Creative Commons license, unless indicated otherwise in a credit line to the material. If material is not included in the chapter's Creative Commons license and your intended use is not permitted by statutory regulation or exceeds the permitted use, you will need to obtain permission directly from the copyright holder.

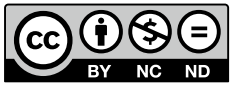

